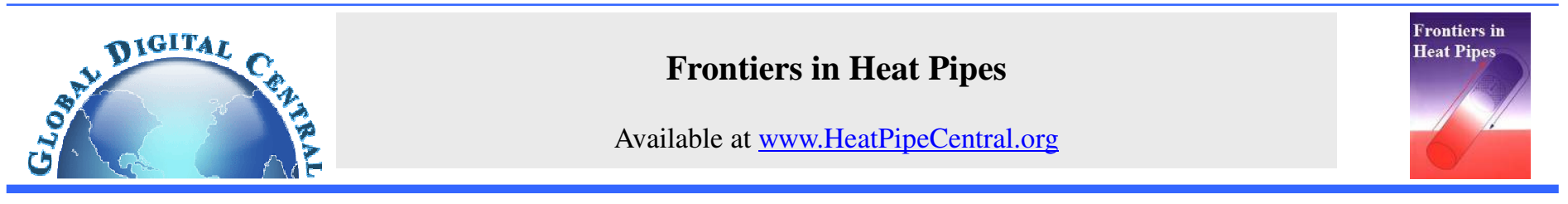

\title{
TEMPERATURE CONTROL WITH TWO PARALLEL SMALL LOOP HEAT PIPES FOR GLM PROGRAM
}

\author{
Dmitry Khrustalev ${ }^{\mathrm{a}, *}$, Chuck Stouffer ${ }^{\mathrm{a}}$, Jentung $\mathrm{Ku}^{\mathrm{b}}$, Jon Hamilton ${ }^{\mathrm{c}}$, Mark Anderson ${ }^{\mathrm{c}}$ \\ ${ }^{a}$ ATK Space, Beltsville, MD, 20705, USA \\ ${ }^{b}$ NASA Goddard Space Flight Center, Greenbelt, MD, USA \\ ${ }^{c}$ Lockheed Martin Space Systems, Palo Alto, CA, 94304, USA
}

\begin{abstract}
The concept of temperature control of an electronic component using a single Loop Heat Pipe (LHP) is well established for Aerospace applications. Using two LHPs is often desirable for redundancy/reliability reasons or for increasing the overall heat source-sink thermal conductance. This effort elaborates on temperature controlling operation of a thermal system that includes two small ammonia LHPs thermally coupled together at the evaporator end as well as at the condenser end and operating "in parallel". A transient model of the LHP system was developed on the Thermal Desktop $^{\mathrm{TM}}$ platform to understand some fundamental details of such parallel operation of the two LHPs. Extensive thermal-vacuum testing was conducted with two thermally coupled LHPs operating simultaneously as well as with only one LHP operating at a time. This paper outlines the temperature control procedures for two LHPs operating simultaneously with widely varying sink temperatures. The test data obtained during the thermal-vacuum testing, with both LHPs running simultaneously in comparison with only one LHP operating at a time, are presented with detailed explanations.
\end{abstract}

Keywords: Two-phase; temperature control; capillary wick.

\section{INTRODUCTION}

Methods of controlling a single loop heat pipe (LHP) operating temperature were reviewed and summarized by $\mathrm{Ku}$ (2008). The most established approach is to maintain the reservoir temperature at a certain level (pre-selected set point temperature) by adding a relatively small amount of thermal energy to the reservoir utilizing a control heater in on/off mode with a feedback loop monitoring reservoir temperature. Alternatively, the control heater can be placed on the liquid return line as was reported by Bienert et al. (1999). Keeping the reservoir temperature at the set point level in the situation where the sink temperature varies in time while the heat dissipation from the heat source is constant, essentially eliminates temperature excursions on the component being cooled. This simple temperature control technique should be in principle applicable to two parallel LHPs, especially if they are not thermally coupled significantly. The extent to which the two LHP evaporators and condensers are thermally coupled together depends on the system design packaging. Possible transient heat flow rates between the two thermally coupled LHP evaporators, as well as between the two condensers, can result in the source temperature fluctuations unless operating temperatures of both loops are actively controlled. An extreme outcome of such thermal interaction can be only one LHP transporting the entire heat dissipated by the source accompanied by forcing the other LHP to become dormant. Since the two LHPs for GLM are strongly thermally coupled due to the system packaging, several aspects of operating the two LHPs simultaneously as well as one LHP at a time have been investigated for this particular application described below. The test data presented in this paper demonstrate that both LHPs can operate simultaneously in a stable and controlled manner.

\section{GLM SYSTEM OVERVIEW, THERMAL REQUIREMENTS AND LHP CONFIGURATION}

The Geostationary Lightning Mapper (GLM), shown in Figure 1, will locate and measure lightning in the Western hemisphere from geostationary orbit. The focal plane array (FPA) electronics interface with the LHP evaporators is only $4.5 \mathrm{~cm} \times 8.8 \mathrm{~cm}$ and the expected constant heat dissipation is bounded by the range from $75 \mathrm{~W}$ to $105 \mathrm{~W}$. The tight system component packaging around the LHP evaporators requires the use of $13 \mathrm{~mm}$ diameter evaporators and $10 \mathrm{~W}$ startup heaters. The expected effective interface material heat transfer coefficients are $4650 \mathrm{~W} /\left(\mathrm{m}^{2}-\mathrm{K}\right)$ for the evaporator interface footprint and $1938 \mathrm{~W} /\left(\mathrm{m}^{2}-\mathrm{K}\right)$ for the condenser plate interface footprint of 90 $\mathrm{mm} \times 530 \mathrm{~mm}$. Operating temperature of the heat pipe-based radiator (not shown in Figure 1) interfaced with the LHP condenser plate, is anticipated to vary between $-10^{\circ} \mathrm{C}$ and $+12^{\circ} \mathrm{C}$ with some short-term excursions to $+25^{\circ} \mathrm{C}$ with the rate of temperature change less than 1 $\mathrm{K} /$ minute. The LHP working fluid is anhydrous ammonia. The LHP primary evaporator wick is made of porous metal with pore radius of approximately 1.5 micrometers.

The main thermal requirement is to keep the FPA side of the LHP evaporator interface at $25^{\circ} \mathrm{C} \pm 2^{\circ} \mathrm{C}$ for any operating radiator temperature between $-10^{\circ} \mathrm{C}$ and $+12^{\circ} \mathrm{C}$, including the time periods when the radiator operating temperature is transitioning between $-10^{\circ} \mathrm{C}$ and

*Corresponding author. Email: Dmitry.Khrustalev@ATK.com 

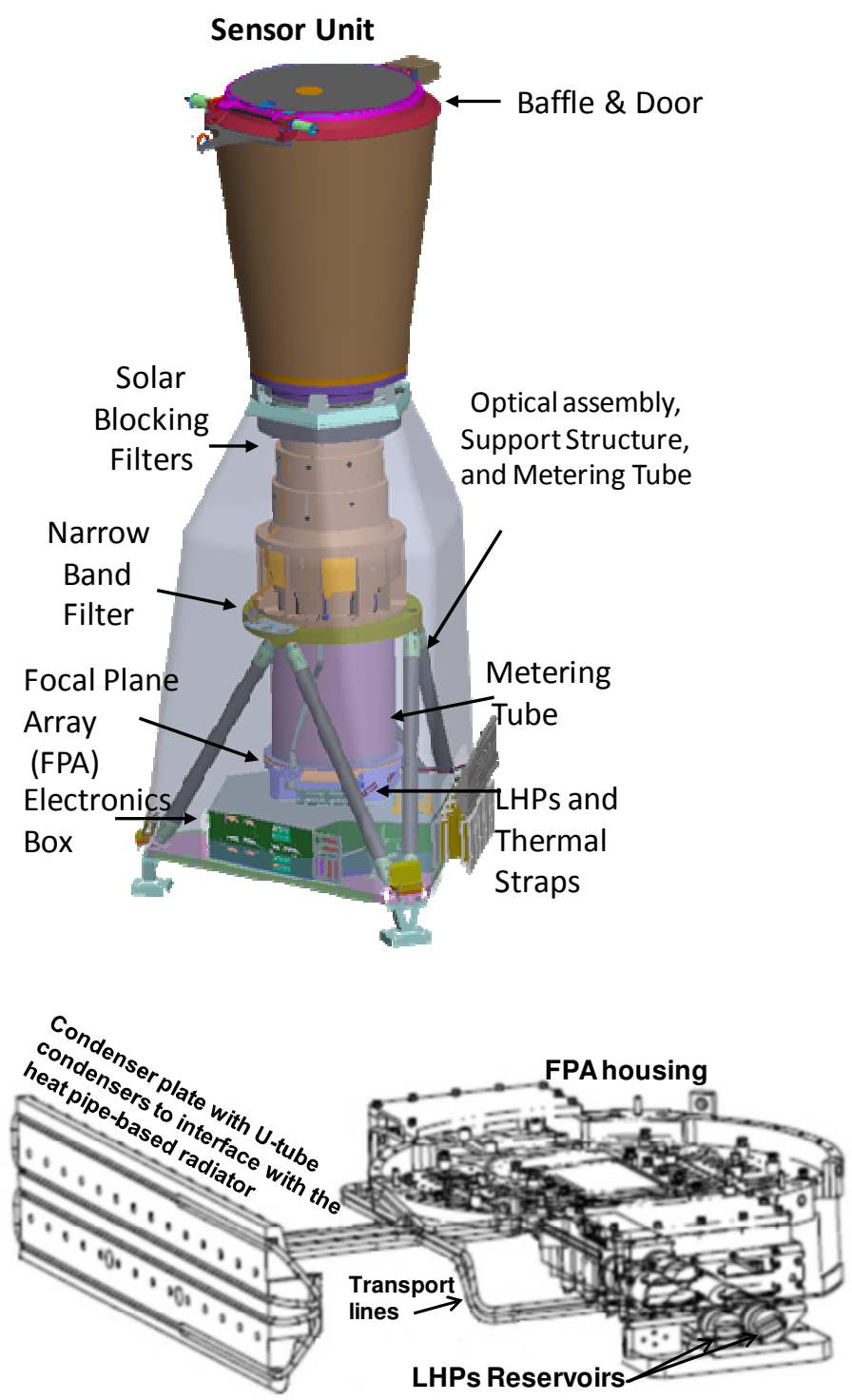

Fig. 1 View of the GLM instrument (Christian and Gheno, 2012) and FPA-LHP assembly packaging

$+12^{\circ} \mathrm{C}$. Such temperature control is required for only one LHP operating at a time as well as for both LHPs operating simultaneously.

The temperature controlling function of the LHPs is achieved by heat loading the LHP reservoir to maintain its temperature at a predetermined level using the reservoir control heaters ( $6.5 \mathrm{~W}$ maximum) visible in Figure 2. This figure provides an image of the two LHPs coupled together and attached to a temporary support frame. The condenser plate is designed to be bolted to a heat pipe-based radiator with multiple bolts. The two U-tube condensers $(3 \mathrm{~mm}$ outer diameter tubing) are soldered into the left and right sides of the condenser plate symmetrically, with the liquid return lines close to the plate central axis. The vapor inlets into the condensers are located at the outer sides of the condenser plate. The two evaporators are integrated into one aluminum block (45 mm x $88 \mathrm{~mm} \times 17 \mathrm{~mm}$ ) interfacing with the FPA surface through an interface material and thus are strongly coupled together thermally. The small diameter transport lines $(3 \mathrm{~mm}$ outer diameter tubing) provide sufficient vibration isolation between the FPA and radiator. The two reservoirs are supported by a stainless steel bracket bolted to the FPA housing for structural integrity. This bracket also provides some thermal conductance between the FPA housing and the reservoirs. The reservoirs are shaped as cylinders approximately 125 $\mathrm{mm}$ long with outer diameters of $18 \mathrm{~mm}$ to fit into the allocated volume. Each evaporator has two startup heaters (10W each) situated on the back surface of the aluminum block interfacing with FPA (visible in Figure 5). Additional clarifications on the fluid flow schematics are provided in the next section describing thermal-fluid modeling conducted for the two coupled LHPs on the platform of Thermal Desktop $^{\mathrm{TM}}$.

\section{THERMAL-FLUID MODELING OF TWO COUPLED LHPS}

An image of the Thermal Desktop ${ }^{\mathrm{TM}}$ (Sinda/Fluint) model for two GLM LHPs is shown in Figure 3. The model simulates transient circulation of the two-phase working fluid in the components of the two LHPs (condenser, evaporator, reservoir, and transport lines) and predicts the temperature distribution across the condenser plate. The model simultaneously solves the flow momentum, energy, and mass conservation equations for the two-phase and single-phase fluid flow for each fluid lump and path separately as well as for the two entire fluid submodels. It includes all three heat transfer mechanisms: convective, conductive (conduction in the condenser plate), and radiative (radiation from the environment to the LHP components), and

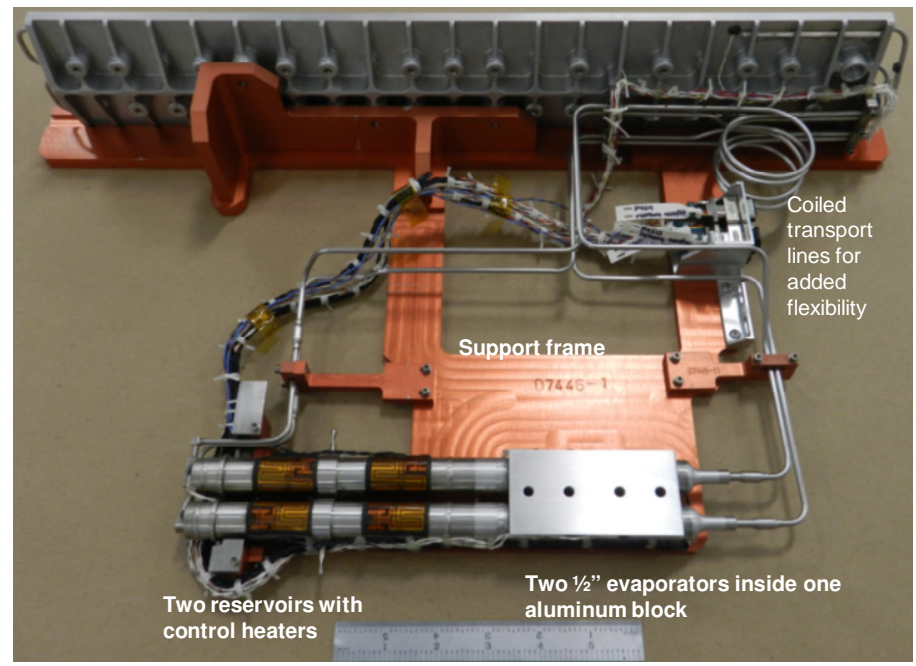

Fig. 2 Two GLM LHPs on a support frame

also accounts for the phase change heat transfer (evaporation and condensation). The modeling technique was documented in detail by Khrustalev (2010) and by Cullimore and Bauman (2000).

One important objective for this transient modeling was to simulate temperature controlling capability of the system utilizing control heaters on the reservoirs, and also to evaluate effect of the parasitic heating of the liquid return lines and reservoirs through radiation from the higher-temperature environment on the overall LHP thermal conductance. Another objective was to investigate if the two LHPs would be naturally sharing the common heat load (from FPA) with and without thermal coupling of the two reservoirs. Understanding gained from the modeling results and observations was useful for designing the LHPs. Figure 3 provides a fluid flow schematic and the temperature color map during steady state operation of the two LHPs with the total heat dissipation from the FPA of $105 \mathrm{~W}$ and the sink (radiator) temperature of $12^{\circ} \mathrm{C}$. The predicted FPA interface temperature with the heat load of $105 \mathrm{~W}$ is $25.29^{\circ} \mathrm{C}$ and temperatures of the two reservoirs are within $0.11^{\circ} \mathrm{C}$ without any kind of control. Temperature of the liquid coming out of the condensers is $12.47^{\circ} \mathrm{C}$ and slightly increases to $13.04^{\circ} \mathrm{C}$ prior to flowing into the reservoir due to the radiation parasitic heating of the transport lines from the environment with temperature of $40^{\circ} \mathrm{C}$. 


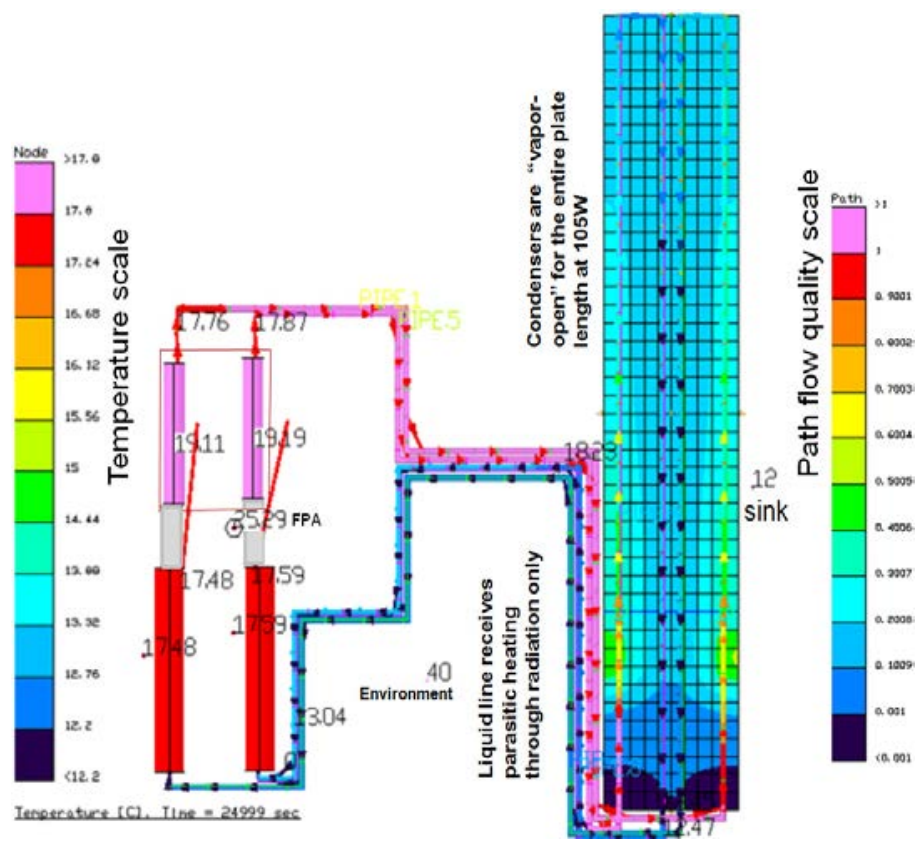

Fig. 3 Thermal Desktop ${ }^{\mathrm{TM}}$ model of two GLM LHPs

The flow quality in the condensers and transport lines can be read using the color quality scale on the right of Figure 3: The outer lines of the condensers are not soldered to the condenser plate for a length of 50 $\mathrm{mm}$ and therefore contain vapor with quality of 1 (red color). The temperature distribution on the condenser plate can be observed using the color temperature scale on the left. Without applying control power to the reservoirs, the two condensers in Figure 3 contain two-phase fluid in the outer passes and single phase subcooled liquid on most length of the central lines of the condensers. Figure 4 presents a steady state with the sink temperature of $-16^{\circ} \mathrm{C}$ and $6.5 \mathrm{~W}$ of the control power applied to each reservoir in order to maintain the FPA interface at $24.62^{\circ} \mathrm{C}$. Since the temperature difference between the saturated vapor and the condenser plate is at the level of $30^{\circ} \mathrm{C}$, the vapor condenses on a short length near the vapor lines entering the condenser plate and the rest of the condenser length is liquid-blocked. Having two-phase flow in the condenser on the entire length of the condenser plate at $105 \mathrm{~W}$ (see Figure 3) is perceived as a situation where the two LHPs are naturally sharing the common heat load. Maintaining an equal heat load sharing between the two LHPs with total heat loads of $75 \mathrm{~W}$ or lower, where the length of the two-phase flow is shorter than the condenser plate, will require the reservoirs to be controlled at the same set point temperature using control heaters. Generally, the heat load sharing can be achieved by keeping the reservoirs temperatures at the same predetermined level by utilizing the control heaters for any heat load level on the evaporator interface. These statements are supported by the test data obtained during thermal-vacuum testing outlined in the following section.

\section{THERMAL-VACUUM TEST SETUP}

The test configuration for GLM LHPs is shown in Figure 5. The 5-kg aluminum block representing the FPA housing is held by four adjustable low-conductivity threaded rods with additional nonconductive supports, bolted to the test frame. Thermal interface gaskets were installed on the evaporator saddle and condenser plate operating interfaces. Six DC power supplies were used to power two control heaters, two startup heaters, cartridge heaters inside the 5-kg block, and also a cover heater shown in Figure 6. A data acquisition system (DAS) was recording readings from multiple thermocouples, thermistors, and with Qcontrol=6.5 W

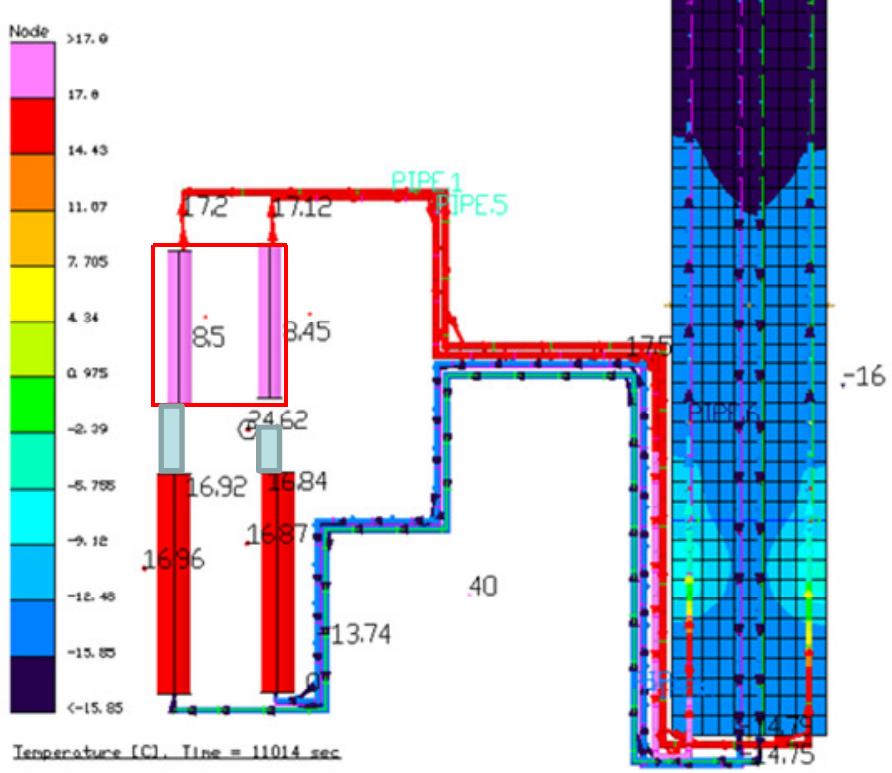

Fig. 4 Liquid blocking of the condensers in the temperature control mode with $6.5 \mathrm{~W}$ per reservoir and cold sink

heaters once per second. The DAS program allowed the control heaters to be turned on/off based on a pre-selected temperature sensor reading. To eliminate heat exchange with the vacuum chamber, the five surfaces of the $5-\mathrm{kg}$ aluminum block surfaces were covered with several layers of multi-layer insulation (MLI). Also the entire test frame was additionally blanketed with hanging MLI blankets. To more accurately simulate the environmental heating through radiation to the reservoirs and transport lines, an aluminum heated cover, shown in Figure 6, was placed above the two reservoirs. The cover temperature was kept $25^{\circ} \mathrm{C}$ above the FPA-side pedestal (see Figure 7) temperature as soon as the cartridge heaters inside the $5-\mathrm{kg}$ aluminum block were turned on. Locations of multiple type-T thermocouples and flight thermistors are shown in Figures 6 through 8. Thermocouples numbered form 62 to 70 (Figure 7) were used to calculate the average pedestal perimeter temperature, TrPa. Thermocouples with numbers from 18 to 21 and from 30 to 33 were used to calculate the average cold plate perimeter temperature $\mathbf{T}_{\text {sink. }}$ The overall system conductance, $\mathbf{C}(\mathrm{W} / \mathrm{K})$, including the LHP evaporator, condenser, and corresponding interfaces with the heat source and sink, is defined herein as follows

$$
C=Q /\left(T_{F P A}-T_{\text {sink }}\right)
$$

where $\mathrm{Q}$ is the electrical power dissipated by the cartridge heaters inside 5-kg aluminum block assuming an infinitesimal heat loss. An outline of the typical functional thermal-vacuum testing sequence is provided below.

\section{TEST PROCEDURE SEQUENCE AND TEST DATA DISCUSSION}

The main objectives of the thermal-vacuum testing included the following:

1. Evaluate and demonstrate the temperature controllability with the two GLM LHPs running simultaneously. 


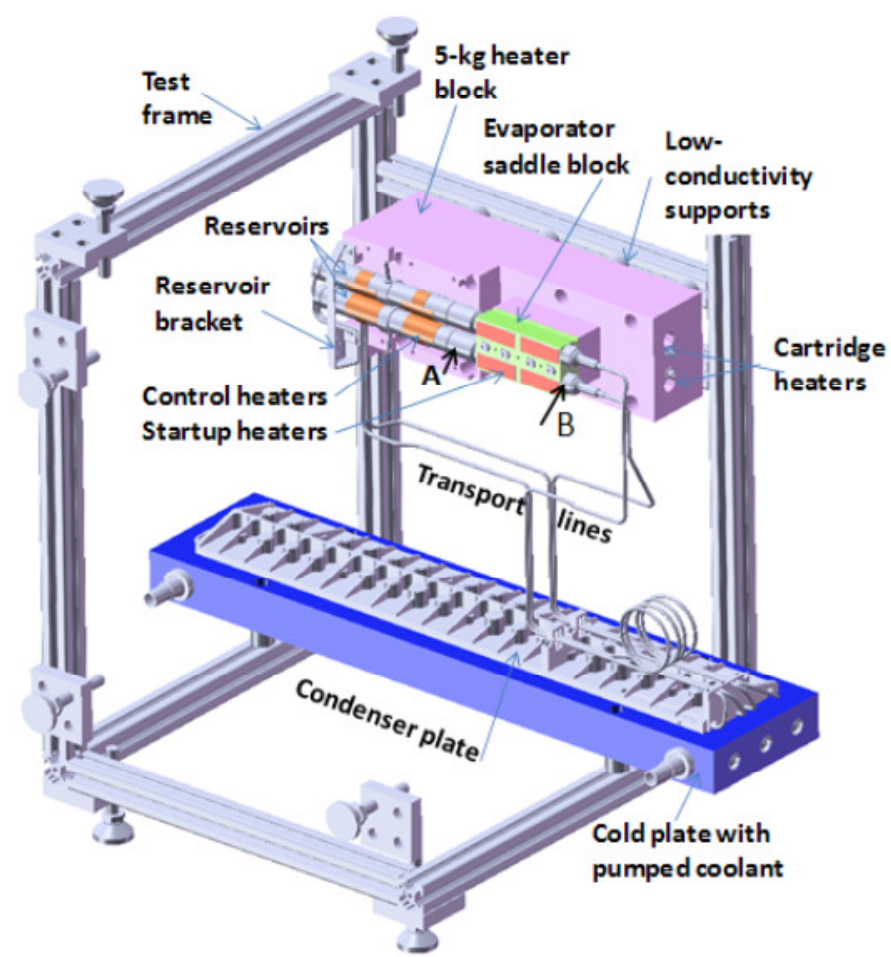

Fig. 5 Test setup configuration

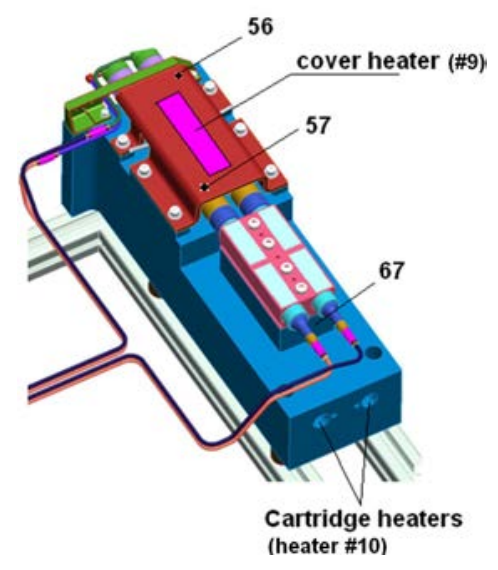

Fig. 6 Heated cover generating environmental heating to reservoirs

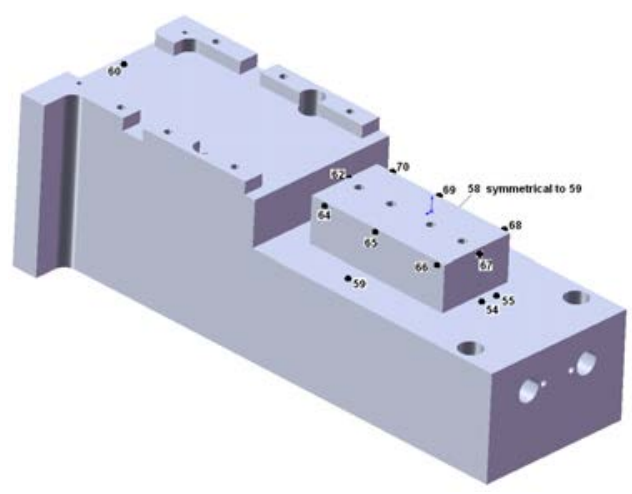

Fig. 7 Heated Thermocouple locations at the pedestal perimeter
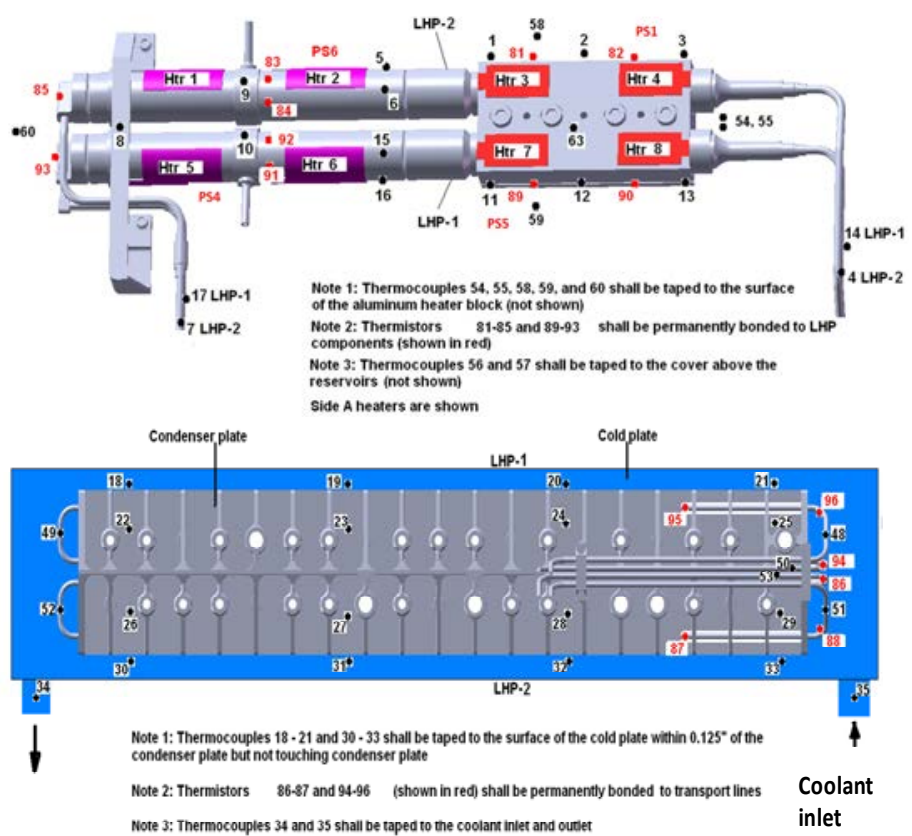

Fig. 8 Thermocouple/thermistor locations on the LHP components and cold plate with pumped coolant

2. Demonstrate the ability to maintain the FPA at $25^{\circ} \mathrm{C} \pm 2^{\circ} \mathrm{C}$ with one LHP running alone or with two LHPs running simultaneously while the sink temperature varies between $-10^{\circ} \mathrm{C}$ and $+12^{\circ} \mathrm{C}$.

3. Measure the overall system conductance for all applicable steady state cases.

The main procedure for temperature control with two LHPs operating simultaneously was Independent Reservoir Set Point control (IRSP) with the same temperature set point for both reservoirs.

From the multiplicity of thermal tests conducted for the GLM LHPs, two most representative "functional" tests are presented below by the plots for temperatures and heat loads versus time with explanations corresponding to different stages of the tests. While the "functional" test was repeated multiple times for three LHP orientations and different heat loads, test results from the orientation shown in Figure 5 and the heat load of $75 \mathrm{~W}$ on the $5-\mathrm{kg}$ aluminum block are used for illustration in this paper.

\subsection{Overview of Startup and Temperature Control Method}

Startup of the LHP at low reservoir and evaporator temperature are more difficult for two reasons: 1) the high surface tension of the working fluid; and 2) the slope of the derivative $\mathrm{dP} / \mathrm{dT}$ is smaller at lower temperatures. Past experience indicates that ammonia loops could start successfully for temperature at $15^{\circ} \mathrm{C}$ or higher. To simplify the test procedure, it was decided that the loop startup would not be initiated until temperatures of the evaporator and reservoir were raised to $15^{\circ} \mathrm{C}$ or above. Startup is conducted by turning on the two startup heaters on the evaporator block. Usually only one of the loops will start. The startup of the second loop is performed by raising the temperature of the reservoir of the operating loop several degrees so that the evaporator temperature will be higher than the reservoir temperature of the yet-to-start loop.

The following major stages of the "functional" test have been distinguished and are marked correspondingly in the graphics below: 
Stage 1: Arriving at a repeatable conditions with the sink temperature of $-35^{\circ} \mathrm{C}$ and pre-heated reservoirs at $+15^{\circ} \mathrm{C}$.

Stage 2: Startup of the first LHP with startup heaters and consequent heat loading of the $5-\mathrm{kg}$ aluminum block at $75 \mathrm{~W}$.

Stage 3: Gradual elevation of the sink temperature to $+5^{\circ} \mathrm{C}$ and controlling the operating LHP.

Stage 4: Startup of the second LHP with startup heaters and controlling reservoirs with control heaters to maintain the FPA interface at $+25^{\circ} \mathrm{C}$.

Stage 5: Variation of the sink temperature from $+5^{\circ} \mathrm{C}$ to $-10^{\circ} \mathrm{C}$, then to $+5^{\circ} \mathrm{C},+25^{\circ} \mathrm{C}$, and back to $+5^{\circ} \mathrm{C}$ while keeping the FPA interface at $+25^{\circ} \mathrm{C}$ (up to $35^{\circ} \mathrm{C}$ for the hot sink at $25^{\circ} \mathrm{C}$ ).

Stage 6: Shutting down circulation inside the LHPs by applying $5 \mathrm{~W}$ to the reservoirs.

\subsection{Test Results with Both Loops Operating Simultaneously}

The top (first) pane of the test data graph in Figure 9, as well as in the consecutive figures, shows temperatures of the LHPs components and sink varying versus time. The second pane monitors rate of the temperature change on the FPA interface. The $3^{\text {rd }}$ pane is for the heat load on the $5-\mathrm{kg}$ block (FPA). The $4^{\text {th }}$ pane is for the heat loads generated by the two startup heaters and two control heaters on the two LHPs. Finally, the $5^{\text {th }}$ pane plots the overall system conductance as defined by equation (1), specifically for steady state operation points.

Figure 9 covers the first four stages of the test and its description below is further divided into multiple steps for a higher resolution on time.

Step 1: Warming the block and evaporators. Since the evaporator and reservoir temperatures were below $+15^{\circ} \mathrm{C}$, startup heaters were turned on at 9:44 (one per LHP) at $10 \mathrm{~W}$ each, simultaneously with the reservoir heaters keeping reservoirs at the same temperature as evaporators $\left(+1^{\circ} \mathrm{C} /-0^{\circ} \mathrm{C}\right)$.

Step 2: As soon as the LHP evaporators and the 5-kg aluminum block were at/above $15^{\circ} \mathrm{C}$, all heaters were turned off at 10:34.

Step 3: Reservoir heating was done from 10:34 to 11:04 by utilizing heaters on both reservoirs to maintain their temperatures above the temperature of evaporators for about 30 minutes to yield repeatable conditions without fluid circulation in LHPs. All heaters were turned off at 11:04.

Step 4: Starting with $10 \mathrm{~W}$ on two startup heaters. One startup heater on each LHP was turned on at 11:06 with $10 \mathrm{~W}$ and fluid circulation in LHP2 started at 11:14 (see Figure 9) with the vapor line temperature at the entrance to the condenser increased to within $5^{\circ} \mathrm{C}$ of the reservoir temperature.

Step 5: $75 \mathrm{~W}$ (nominal FPA heat dissipation) was applied to the aluminum block at 11:16 and both startup heaters were turned off.

Step 6: The cover heater settings were adjusted to allow the cover near the two reservoirs to be heated to a temperature level $25^{\circ} \mathrm{C}$ higher than that on the aluminum pedestal (TC \#67) in the auto-tracking mode.

Step 7: Preventing rapid cooling down. As soon as the reservoir temperature started to decrease due to the cold liquid entering it, the reservoir heater of the operating LHP2 was turned on to prevent a rapid cooling of the block/FPA. The heater power was adjusted to $3 \mathrm{~W}$ and then elevated back to $6 \mathrm{~W}$ to minimize the operating temperature variation. The aluminum pedestal cooling rate peaked at $1.1 \mathrm{~K} /$ minute at $11: 17$ and then reduced.

Step 8: The sink chiller set point temperature was changed to $+5^{\circ} \mathrm{C}$ (from $-41^{\circ} \mathrm{C}$ ) with the temperature rate of change approximately $1.5 \mathrm{~K} /$ minute in order to simulate the sink temperature variation anticipated for the program. The temperature on the LHP evaporators gradually increased to $14^{\circ} \mathrm{C}$ due to the cold plate temperature increase.

Step 9: The LHP reservoir heater power was gradually reduced to zero by 11:50.

Step 10: Turning on LHP2 reservoir heater with the power level of $5 \mathrm{~W}$ at 11:55 $\mathrm{AM}$ and then powering the startup heater on LHP1 resulted in LHP1 startup, at which time the IRSP procedure was initiated at 12:08, keeping the FPA interface at $24^{\circ} \mathrm{C}$.

Step 11: Power levels on both reservoir heaters were adjusted to 6 $\mathrm{W}$ at 12:30. The IRSP procedure with the reservoir set point at $18.4^{\circ} \mathrm{C}$ kept the $5-\mathrm{kg}$ aluminum block temperature (measured on the aluminum pedestal) at approximately $24^{\circ} \mathrm{C}$ during that control heater power adjustment. Continuation of the same test is shown in Figure 10.

Step 12: The cold plate (sink) temperature was varied from $+5^{\circ} \mathrm{C}$ to $-10^{\circ} \mathrm{C}$, kept at $-10^{\circ} \mathrm{C}$ for 40 minutes and then increased back to $5^{\circ} \mathrm{C}$ with the temperature change rate of approximately $1.5 \mathrm{~K} /$ minute. During this sink temperature variation the average pedestal (FPA) temperature stayed between $23.8^{\circ} \mathrm{C}$ and $24.2^{\circ} \mathrm{C}$. The reservoir heaters duty cycles increased with the sink at $-10^{\circ} \mathrm{C}$, with corresponding timeaveraged power levels of $2 \mathrm{~W}$ on LHP1 reservoir and $4 \mathrm{~W}$ on LHP2 reservoir.

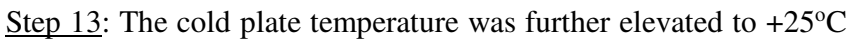
starting at $14: 05$ with the rate of $1.5 \mathrm{~K} /$ minute and then was kept at $+25^{\circ} \mathrm{C}$. During the time period from 14:37 to $15: 00$ the FPA heat load was turned off (for about one minute) and then quickly turned back on eight times without any significant temperature fluctuations on the LHP components. A steady state operation with both LHPs operating was achieved by $16: 30$ (See Figure 11). Although the IRSP procedure was effective all the time, the LHP1 reservoir heater duty cycle was virtually zero and about $1 \mathrm{~W}$ was continuously powered on the LHP2 reservoir heater. The highest aluminum pedestal (FPA) steady state average temperature was $33^{\circ} \mathrm{C}$ at $16: 20$, and the total FPA-sink conductance with both LHPs operating and $25^{\circ} \mathrm{C}$ sink temperature was around $9.5 \mathrm{~W} / \mathrm{K}$ (see Figure 11 bottom pane).

Step 14: The sink temperature was then decreased to $+5^{\circ} \mathrm{C}$ and LHP1 was shut down by 17:15 using the reservoir heater, while LHP2 was kept operating with the sink temperature again elevated to and being maintained at $+25^{\circ} \mathrm{C}$.

Step 15: LHP2 steady state operation was achieved at 17:52 with the highest aluminum pedestal (FPA) steady state average temperature of $33^{\circ} \mathrm{C}$ and corresponding LHP2 conductance of $9.5 \mathrm{~W} / \mathrm{K}$.

Step 16: The main heater (FPA) was turned off at 17:56 and one control heater on each reservoir was powered at $5 \mathrm{~W}$, which stopped circulation in LHP2 within several minutes. The reservoir heater settings were adjusted to keep the reservoir temperature above that of the evaporator.

The overall source-to-sink conductance was $9.5 \mathrm{~W} / \mathrm{K}$ for the sink temperature of $25^{\circ} \mathrm{C}$ with both LHPs operating simultaneously or only one LHP operating with the total heat load of $75 \mathrm{~W}$. This observation is explained by noticing that with one LHP transporting only $37.5 \mathrm{~W}$ (out of $75 \mathrm{~W}$ total) its two-phase length in the condenser is smaller than the cold plate length (variable conductance mode) and the corresponding condenser-interface conductance is much lower than in the situation with the total heat load of $105 \mathrm{~W}$ where the entire cold plate is warmed up by the vapor condensing in the condenser, as shown in Figure 3.

Following this logic, two loop heat pipes operating simultaneously with the heat load of $105 \mathrm{~W}$ should have a higher overall source-to-sink conductance than only one LHP operating at a time. In fact, the test data in Figure 12 (for $105 \mathrm{~W}$ ) do indicate that the overall conductance 
of the two LHPs was $12.5 \mathrm{~W} / \mathrm{K}$ versus the conductance for only LHP1 operating of $9.5 \mathrm{~W} / \mathrm{K}$ and for only LHP2 operating of $9.1 \mathrm{~W} / \mathrm{K}$. The test data in Figure 12 were obtained by adjusting the sink temperature in order to keep the FPA interface at $25^{\circ} \mathrm{C} \pm 1^{\circ} \mathrm{C}$ with minimized control power applied to either of the two LHPs.

The highest sink temperature satisfying this condition was $16^{\circ} \mathrm{C}$ for the case of both LHPs operating simultaneously versus $14^{\circ} \mathrm{C}$ for only one LHP operating at a time. This difference is anticipated to become larger for higher heat loads, providing the motivation to run two LHPs in parallel for higher heat dissipations from FPA.

It is worth noting that turning on the second LHP at 11:00 was achieved easily by simply applying $5.5 \mathrm{~W}$ of the control power to the already running LHP1 reservoir in order to elevate its evaporator temperature and thus directing more of the thermal energy to flow from the $5-\mathrm{kg}$ block to the LHP2 evaporator, starting the flow circulation in LHP2. The same principle was used in order to shut down the flow circulation in LHP1 at 12:45: applying $5.5 \mathrm{~W}$ to LHP1 reservoir for a longer time period did shut it down while LHP2 continued to operate. Also in support of the previous statement that lowering the heat load usually results in a lower LHP conductance, reducing the heat load from $105 \mathrm{~W}$ to $75 \mathrm{~W}$ at $14: 15$ (see Figure 12) led to the LHP2 conductance reduction from $9.1 \mathrm{~W} / \mathrm{K}$ to $8.5 \mathrm{~W} / \mathrm{K}$.

\subsection{Test Results with Only One Loop Operating}

While the FPA temperature control with two LHPs operating simultaneously was demonstrated as presented above, utilizing only one LHP and keeping the second one dormant is discussed below. Figure 13 presents test data obtained with only LHP1 running during a similar complete "functional" test while applying approximately $1 \mathrm{~W}$ (timeaveraged) to LHP2 reservoir to make sure it does not start the fluid circulation. This test with only one LHP functioning is discussed below.

Step 1: Warming the block and evaporators. Since the evaporator and reservoir temperatures prior to the test beginning were below $+15^{\circ} \mathrm{C}$, two startup heaters were turned on at $8: 45$ (one per LHP) at $10 \mathrm{~W}$ each simultaneously with the reservoir heaters keeping reservoirs at the same temperature with evaporators $\left(+1^{\circ} \mathrm{C} /-0^{\circ} \mathrm{C}\right)$.

Step 2: As soon as the LHP evaporators and the 5-kg aluminum block were at/above $15^{\circ} \mathrm{C}$, all heaters were turned off at 10:07.

Step 3: Reservoir heating was done from 10:07 to $10: 37$ by utilizing heaters on both reservoirs to maintain their temperatures above the temperature of evaporators for at least 30 minutes. All heaters were turned off at 10:37.

Step 4: Starting with $10 \mathrm{~W}$ on two startup heaters. One startup heater on each LHP was turned on at 10:38 with $10 \mathrm{~W}$ and fluid circulation in LHP1 started at 10:47 (see Figure 13) with the vapor line temperature at the entrance to the condenser sharply increased to within $5^{\circ} \mathrm{C}$ of the reservoir temperature.

Step 5: $75 \mathrm{~W}$ (nominal FPA power) was applied to the aluminum block and both startup heaters were turned off.

Step 6: The cover heater settings were adjusted to allow the cover near the two reservoirs to be heated to a temperature level $25^{\circ} \mathrm{C}$ higher than that on the aluminum pedestal (TC \#67) in the auto-tracking mode.

Step 7: Preventing rapid cooling down. As soon as the LHP1 reservoir temperature started to decrease due to the cold liquid entering it, power was applied to the reservoir heater of the operating LHP1 to prevent a rapid cooling of the block/FPA. The aluminum pedestal cooling rate peaked at $1.5 \mathrm{~K} /$ minute at 10:45 and then reduced to $+/-0.5 \mathrm{~K} /$ minute for the rest of the test. The reservoir heater power level was then increased to $6 \mathrm{~W}$.

Step 8: The chiller set point temperature was changed to $5^{\circ} \mathrm{C}$ (from $-41^{\circ} \mathrm{C}$ ) with the temperature rate of change approximately 1.5 $\mathrm{K} /$ minute. The temperature on the LHP evaporators gradually elevated to $11^{\circ} \mathrm{C}$ due to the cold plate temperature increase.

Step 9: The LHP1 reservoir heater power was gradually reduced to zero by $11: 15$.

Step 10: An operational steady state was achieved by 11:45 with LHP1 transporting $75 \mathrm{~W}$ to the cold plate at $4^{\circ} \mathrm{C}\left(5^{\circ} \mathrm{C}\right.$ sink $)$ with LHP1 conductance of $8.5 \mathrm{~W} / \mathrm{K}$.

Step 11: Power level on the LHP1 reservoir heater was adjusted to $6 \mathrm{~W}$ and the IRSP procedure was applied to LHP1 with the reservoir set point at $18^{\circ} \mathrm{C}$ in order to bring the $5-\mathrm{kg}$ block and pedestal to $24.5^{\circ} \mathrm{C}$.

Step 12: With the reservoir set point of $18^{\circ} \mathrm{C}$, the steady state average pedestal (FPA) temperature was maintained at approximately $24.5^{\circ} \mathrm{C}$ at $12: 30$.

Step 13: The cold plate (and the "sink") temperature was varied from $+5^{\circ} \mathrm{C}$ to $-10^{\circ} \mathrm{C}$, kept at $-10^{\circ} \mathrm{C}$ for 40 minutes and then increased back to $+5^{\circ} \mathrm{C}$ with the temperature change rate of approximately $1.5 \mathrm{~K} /$ minute. During this sink temperature variation the average pedestal (FPA) temperature stayed between $24^{\circ} \mathrm{C}$ and approximately $24.5^{\circ} \mathrm{C}$. The reservoir heaters duty cycle was at its maximum with the sink at $-10^{\circ} \mathrm{C}$, with corresponding time-averaged power on the LHP1 reservoir of $6 \mathrm{~W}$.

Step 14: The cold plate temperature was further elevated to $+25^{\circ} \mathrm{C}$ starting at 13:45 with the rate of $1.5 \mathrm{~K} /$ minute and then was kept at $+25^{\circ} \mathrm{C}$ to achieve a steady state with only LHP1 operating. The LHP1 reservoir heater duty cycle was zero at the steady state at 14:35. The highest aluminum pedestal (FPA) steady state average temperature was $33^{\circ} \mathrm{C}$, which means the total FPA-sink conductance with LHP1 operating at $25^{\circ} \mathrm{C}$ sink temperature was $8 \mathrm{~W} / \mathrm{K}$.

Step 15: The sink temperature was then decreased to $+5^{\circ} \mathrm{C}$ and the reservoir heater on LHP1 was powering with some duty cycle, keeping the LHP1 reservoir at $18^{\circ} \mathrm{C}$ (and with also about $1 \mathrm{~W}$ time-averaged heating on LHP2 reservoir).

Step 16: The main heater (FPA) was turned off at 15:03 and LHP1 reservoir heater was powered at $5 \mathrm{~W}$ (and heating on LHP2 reservoir increased to $3.5 \mathrm{~W}$ time-averaged), which stopped circulation in LHP1 within several minutes. The reservoir heater controller settings were adjusted to keep reservoir temperatures above those of the evaporators.

\section{SUMMARY AND CONCLUSIONS}

1. Test data demonstrated that two parallel LHPs thermally coupled on the evaporator end as well as on the condenser end, could operate simultaneously ("heat load sharing mode") and provide the temperature controlling function for the heat source during the sink temperature variation. Alternatively, only one LHP could be operated at a time in the temperaturecontrol mode while the other LHP was kept "dormant" by applying a small heat load of approximately $1 \mathrm{~W}$ (timeaveraged) to its reservoir.

2. The main method/procedure used to keep both LHPs operating simultaneously during the sink transients was Independent Reservoir Set Point Control (IRSP) where two reservoirs were kept at the same set point temperature by utilizing reservoir control heaters in the on/off mode. 


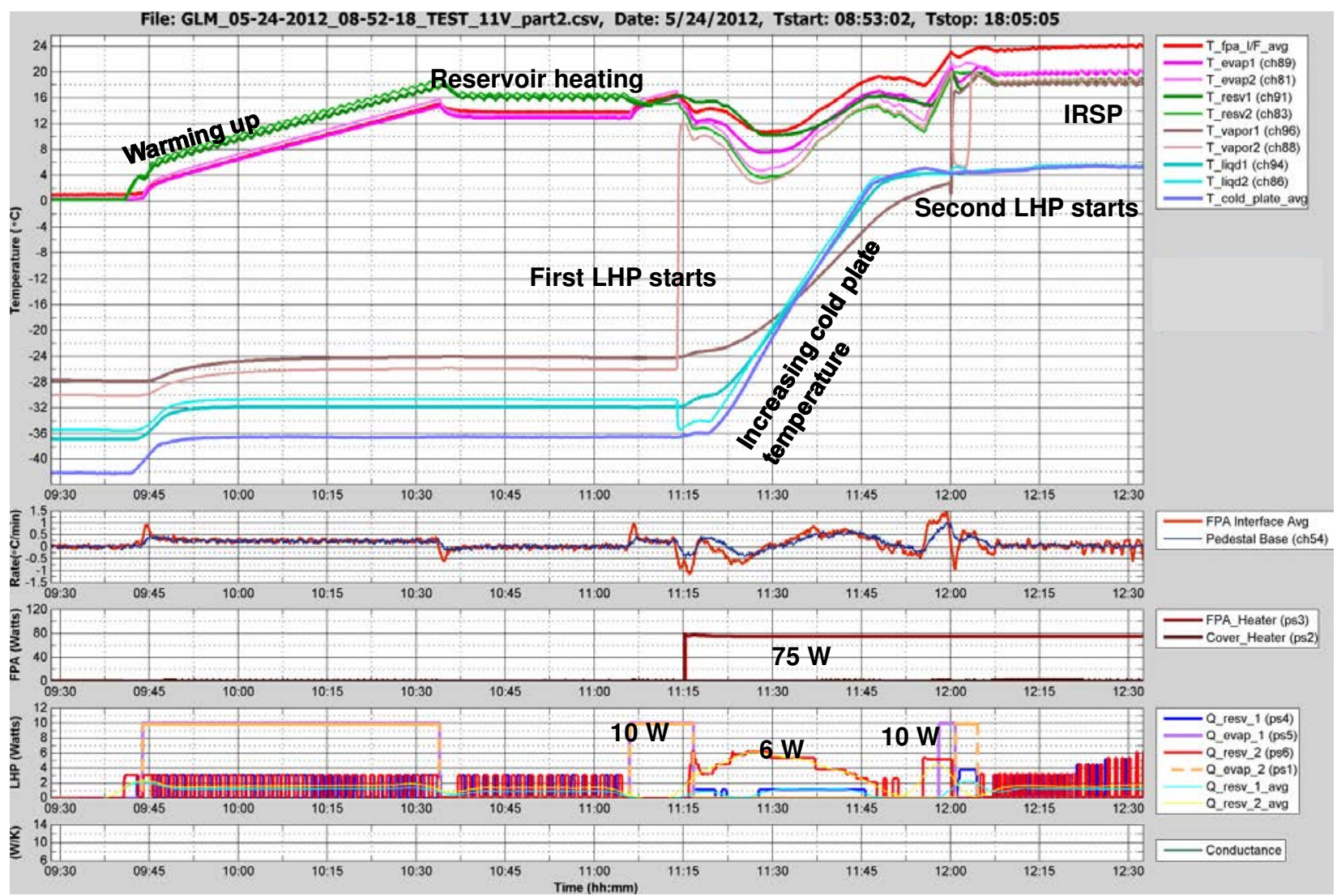

Fig. 9 Initial stages of the "functional" test: startup of the first and second LHPs

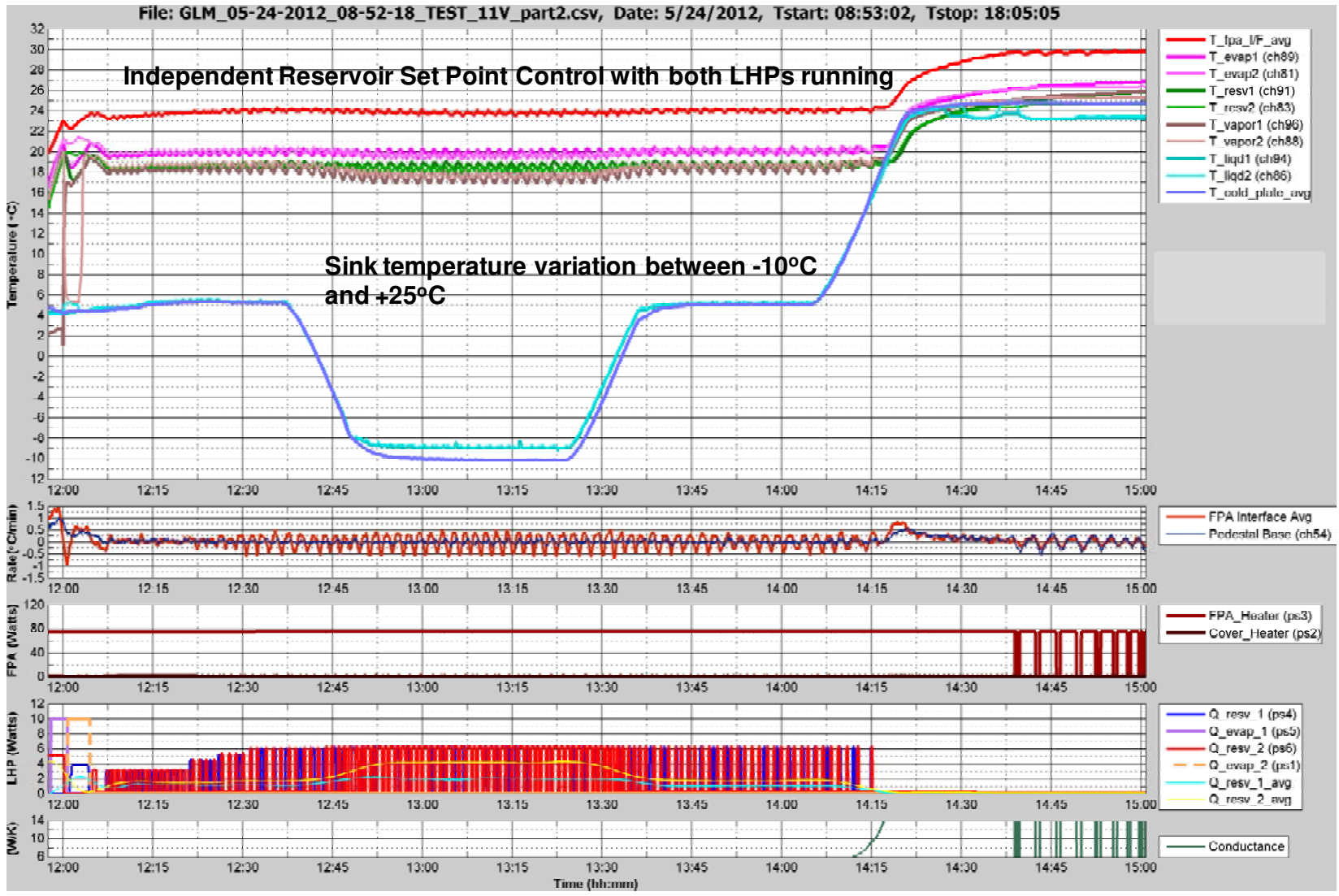

Fig. 10 Sink temperature variation with FPA interface maintained at $+25^{\circ} \mathrm{C}$ 


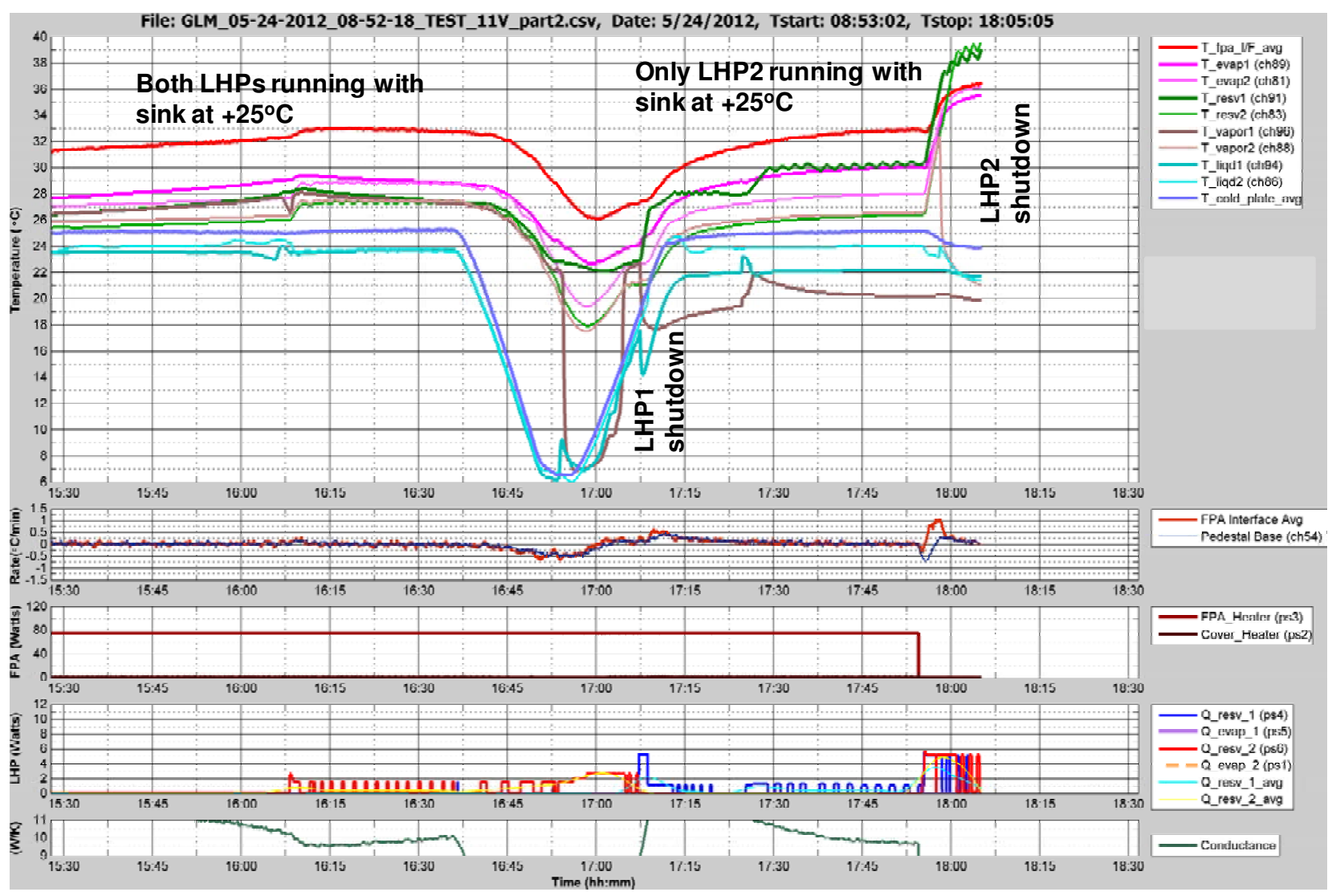

Fig. 11 Comparison of both LHPs operating with one LHP operating at the sink temperature of $+25^{\circ} \mathrm{C}$

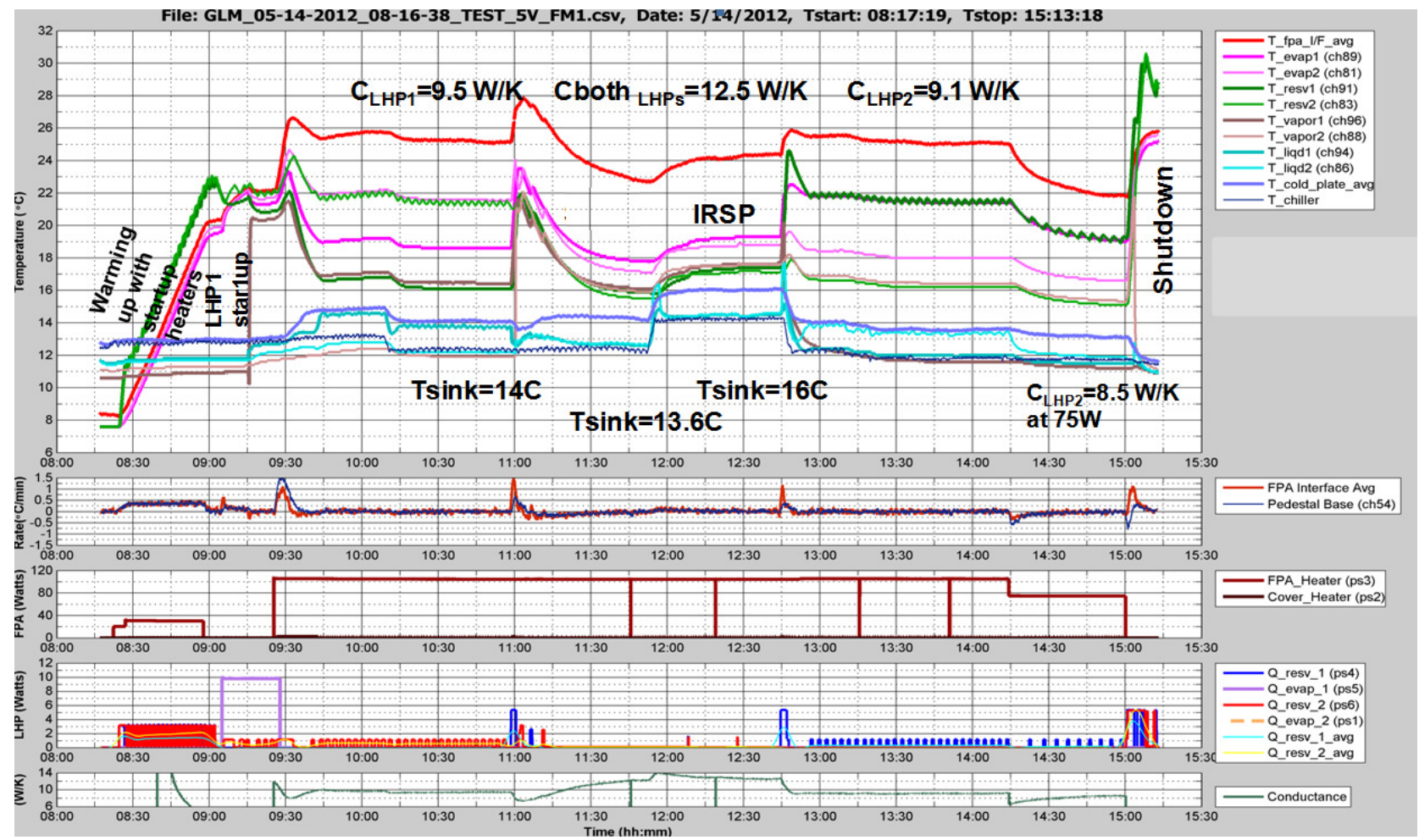

Fig. 12 Conductance comparison between both LHPs operating and only one LHP operating at $105 \mathrm{~W}$ 


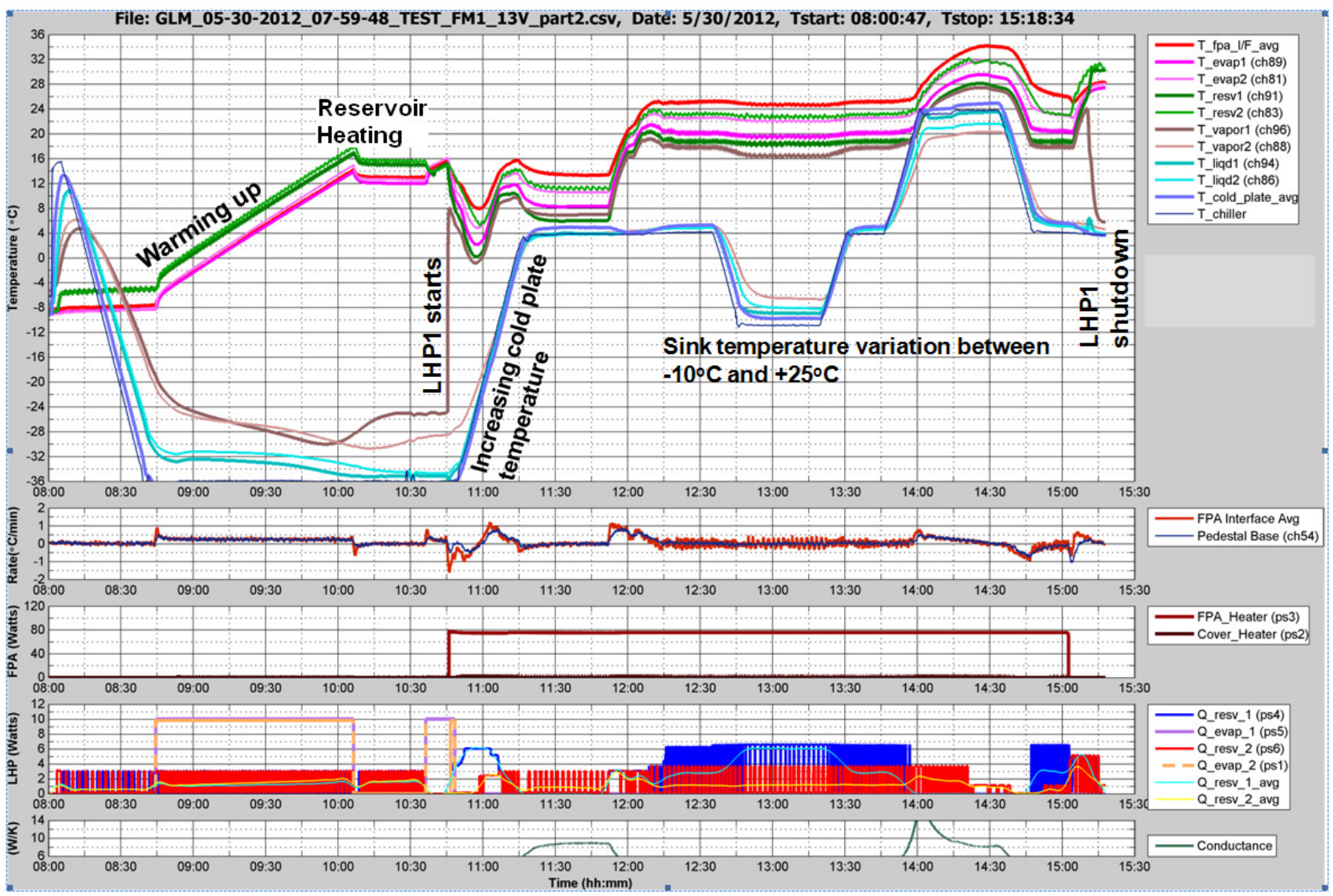

Fig. 13 Functional test with only LHP1 operating and controlling FPA temperature

3. The overall source-to-sink conductance (including the evaporator and condenser interfaces) was $12.5 \mathrm{~W} / \mathrm{K}$ for the case of both LHPs operating simultaneously with the highest heat load of $105 \mathrm{~W}$ versus $9.5 \mathrm{~W} / \mathrm{K}$ for only one LHP working. For the lowest heat load of $75 \mathrm{~W}$ though, there was no gain in the conductance for both LHPs operating versus only one LHP running at a time ( 9.5 $\mathrm{W} / \mathrm{K}$ for either case). This is explained by the naturally occurring liquid blocking of the condenser end, which is more pronounced for lower power levels and results in a non-uniform temperature of the condenser plate interfacing with the sink.

4. Starting the first LHP from the controlled conditions was repeatedly done (and with the success rate of 100\%) by applying only $10 \mathrm{~W}$ per heater to the two startup heaters. Subsequently starting the second LHP with the first LHP already operating at the heat load of $75 \mathrm{~W}$ or $105 \mathrm{~W}$ was done multiple times by first applying a control heater power of several Watts to the operating LHP reservoir and then turning on the startup heater on the second LHP.

5. Keeping the FPA interface temperature at $25^{\circ} \mathrm{C} \pm 1^{\circ} \mathrm{C}$ with the cold plate (sink) temperature of $-10^{\circ} \mathrm{C}$ was achieved within the control power budget of $6.5 \mathrm{~W}$ per LHP, as had been predicted by the thermal analyses.

6. The LHP system developed for GLM can be operated with only one LHP running or both LHPs running on demand, which means that the LHP system can be considered as fully redundant while still offering an option to increase the overall source-to-sink conductance by turning on the second LHP in a hypothetical situation with a significantly elevated heat dissipation from the source.

\section{ACKNOWLEDGEMENTS}

Authors acknowledge NASA/NOAA funding and overall program guidance.

\section{NOMENCLATURE}

C conductance (W/K)

Q heat flow rate (W)

$\mathrm{T}$ temperature $(\mathrm{K})$

$\mathrm{t}$ time (seconds)

Subscripts

avg average

cond condenser

ev evaporator

res reservoir

Acronyms

FPA Focal Plane Array

GLM Geostationary Lightning Mapper

IRSP Independent Reservoir Set Point control

LHP Loop Heat Pipe

MLI Multi-layer insulation

\section{REFERENCES}

$\mathrm{Ku}$, J, 2008, "Methods of Controlling the Loop heat Pipe Operating Temperature," Proceedings of the 33rd International Conference on Environmental Systems,” (ICES), SAE Technical Paper 2008-011998, 2008.

http://dx.doi.oirg/doi:10.4271/2008-01-1998 
Bienert, W., Krotiuk, W., and Nikitkin, M. 1999, "Thermal Control with Low Power, Miniature Loop Heat Pipes," Proceedings of $29^{\text {th }}$ International Conference on Environmental Systems, (ICES), SAE Technical Paper 1999-01-2008, 1999.

http://dx.doi.org/11.3163/2008-01-1999.

Khrustalev, D., 2010, “Advances in Transient Modeling of Loop Heat Pipe Systems with Multiple Components," Proceedings of Space, Propulsion \& Energy Sciences International Forum (SPESIF) 2010, Laurel, MD, Applied Physics Laboratory, March 18-20, 2010.
Cullimore, B., and Bauman, J., 2000, "Steady State and Transient Loop Heat Pipe Modeling," Proceedings of the 34th International Conference on Environmental Systems," (ICES), SAE 2000-01-2316.

Christian and Gheno, 2012, "Geostationary Lightning Mapper," American Meteorological Society (AMS) 92nd Annual Meeting, January 24, 2012. 